


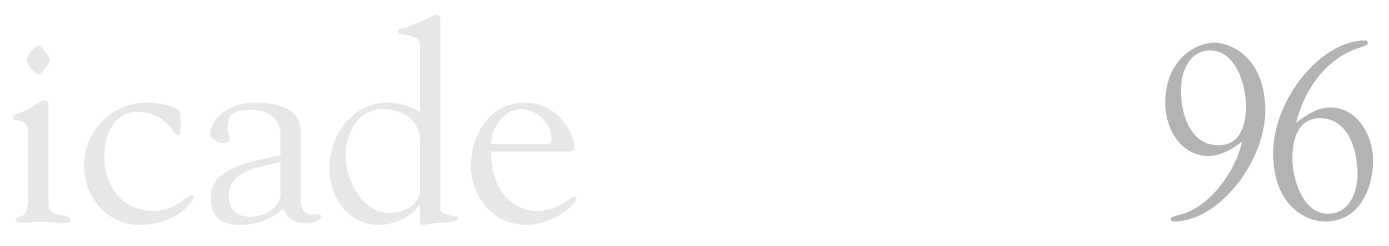

Miscelánea 



\title{
LIMITACIONES DE LA EFICIENCIA ECONÓMICA COMO CRITERIO NORMATIVO: ORIGEN Y CONSECUENCIAS
}

\author{
Autor: Zulema Calderón Corredor ${ }^{1}$ \\ Profesora Contratada Doctora \\ Área de Derecho Financiero y Tributario \\ Área de Filosofía del Derecho \\ Universidad Francisco de Vitoria
}

\section{Resumen}

La eficiencia económica inspirada en la teoría económica neoclásica se ha convertido en un criterio valorativo fundamental en la toma de decisiones económicas, empresariales, políticas y sociales. En este trabajo se apuntan algunas de las claves antropológicas y filosóficas que históricamente han inspirado su configuración, elementos que han acompañado la historia del pensamiento económico y que han inspirado las hipótesis de trabajo adoptadas y los modelos de persona y de acción objeto de estudio. El análisis anterior permite apuntar algu-

\footnotetext{
${ }^{1}$ z.calderon.prof@ufv.es
} 


\title{
Zulema Calderón Corredor
}

nas de sus limitaciones así como las consecuencias que se derivan de la aplicación de la eficiencia como criterio normativo.

Palabras clave: eficiencia económica; historia económica; utilitarismo; antropología; Ética; libertad moral; thelos; individualismo metodológico; economía neoclásica; preferencias subjetivas; bienestar; altruismo; reciprocidad.

\section{Limitations of economic efficiency as normative criterion: origin and con- sequences}

\begin{abstract}
Economic efficiency inspired by the neoclassical economic theory, has become a fundamental valuation approach in making economic, business, political and social decisions. In this paper we suggest some of the philosophical and anthropological keys that have historically inspired its configuration, elements that have accompanied the history of economic thought and prompted the working hypotheses and human models adopted under study. This analysis let us to consider some of its limitations and the consequences arising in the implementation of efficiency as a normative criterion.
\end{abstract}

Key words: economic efficiency; economic history; utilitarianism; anthropology; Ethics; moral freedom; thelos; methodological individualism; neoclassical economics; subjective preferences; welfare; altruism; reciprocity.

\section{PLANTEAMIENTO DE LA CUESTIÓN}

La eficiencia económica, entendida como la medición del uso o aprovechamiento de recursos en la producción de bienes y servicios y en la satisfacción de las necesidades humanas, se ha constituido en criterio de valoración y decisión en muchos ámbitos, no solo en los estrictamente económicos o empresariales. Su importancia ha ido en ascenso a la misma velocidad que lo han hecho otros criterios normativos como la utilidad o el bienestar (material) en contextos económicos y políticos. La crisis económica sufrida por muchos Estados occidentales en los últimos años, ha renovado su protagonismo en entornos de escasez de recursos y de reajuste en la oferta de bienes y servicios. 
En el ámbito de la actividad pública, la evaluación del gasto, la adopción de políticas públicas o el re-dimensionamiento de algunas instituciones, se han realizado desde valoraciones centradas en parámetros de eficiencia económica. En materia impositiva, por ejemplo, la cuestión de los principios impositivos de equidad y eficiencia, su significado, vigencia, relación y jerarquía, se encuentra muy presente en la mayoría de las reflexiones sobre la actual reforma impositiva en España, en las tendencias de cambio presentes en fiscalidad internacional y en gran cantidad de aportaciones doctrinales que de forma directa o indirecta abordan la cuestión y toman postura respecto de la misma.

Desde una perspectiva empresarial, la eficiencia económica constituye una variable principal para la toma de decisiones en la valoración de inversiones, de procesos de producción o de actividades empresariales no calificables de tradicionales, como la responsabilidad social corporativa o el emprendimiento social.

En definitiva, la eficiencia económica ha llegado a ocupar un lugar predominante como criterio normativo, no solo en Economía, sino también en el ámbito jurídico-político y como referente en la adopción de decisiones colectivas. Resulta relevante por tanto preguntarse por la virtualidad de este criterio normativo, por sus fundamentos, alcance y limitaciones. De la idoneidad en su diseño e interpretación dependerá también la idoneidad de las decisiones adoptadas conforme al mismo.

En nuestra opinión, el concepto de eficiencia económica que predomina actualmente y que actúa como criterio decisor en cuestiones económicas y no económicas cuenta con elementos que, desde un punto de vista antropológico, pueden limitar su valor o su potencial como criterio normativo. Es decir, el modelo de persona y de acción humana sobre el que se ha definido el concepto predominante de eficiencia y su evaluación, es un modelo que no refleja la identidad fundamental del hombre y de su forma relacional de ser. Algunos de los elementos característicos de este modelo antropológico son: subjetividad o polivalencia en los fines de la acción humana económica, principio de comportamiento económico como criterio fundamental de decisión, olvido del carácter moral de la acción humana, predominio de las preferencias subjetivas y del criterio de utilidad y bienestar material e individualismo metodológico, entre otros.

El objetivo del análisis siguiente es conocer si esos elementos han estado siempre presentes en el estudio económico de la acción humana y en las aportaciones históricas más relevantes sobre la eficiencia. Si no ha sido así, resulta interesante determinar cuándo se han incorporado al pensamiento económico y qué elementos han influido en ese proceso. Esta investigación permitirá conocer mejor algunas de las limitaciones a la eficiencia como criterio normativo. En la medida en que el concepto de eficiencia económica es una elaboración relativamente moderna, se incorporará al análisis el estudio de la acción humana económica y sus elementos como antecedente de la formulación del criterio normativo de 
eficiencia. Creemos además que la pregunta por los fundamentos antropológicos de la acción económica subyace en el estado actual de la Teoría Económica y en los retos que se plantean a esta disciplina. Es una pregunta que demanda una investigación por los fundamentos, por las fuentes, y con ello, por la adopción de una perspectiva más amplia que la de la propia Economía.

Para ello se propone una indagación histórica en los elementos antropológicos implícitos en la acción humana económica y en la eficiencia. También se estudiará el contexto filosófico que ha propiciado la adopción de esos elementos y qué consecuencias se han podido derivar de ello. Con estos objetivos se analizarán fuentes doctrinales que reflexionen sobre los hitos más relevantes de la historia del pensamiento económico desde un punto de vista antropológico y filosófico. Por razones de espacio y de perspectiva, queda fuera de nuestro análisis el repaso detallado de las contribuciones históricas al concepto económico de acción humana o de eficiencia y la profundización en sus fundamentos teóricos o matemáticos.

\section{ANTECEDENTES DEL ANÁLISIS ECONÓMICO: DE LA VIDA BUENA AL JUICIO MORAL}

\subsection{Oikonomia ${ }^{2}$ y vida buena}

Aunque no puede decirse que los antiguos griegos fueran economistas en el sentido moderno del término, pueden encontrarse en la Edad Antigua referencias doctrinales a la cuestión del intercambio de bienes y a la economía. Podemos empezar con Aristóteles, pues aunque es difícil identificar en su doctrina una referencia explícita a la eficiencia, sí desarrolla una teoría sobre la acción humana económica que incorpora elementos antropológicos y filosóficos de interés para el análisis posterior. Esos elementos latentes en sus aportaciones y que posiblemente habrían formado parte de su teoría de la eficiencia económica de haber sido formulada, son los que vamos a analizar.

Sus aportaciones económicas pueden enmarcarse fácilmente en el referente antropológico que contienen su Ética y su Política ${ }^{3}$, y se encuentran acompañadas de una actitud epistemológica de quien cree que "todos los hombres desean por naturaleza saber" y que "sabemos una cosa cuando creemos conocer su causa

\footnotetext{
${ }^{2}$ Estudio de la administración de la unidad familiar o hacienda, en contraposición a la crematística como disciplina que busca acrecentar la riqueza.

${ }^{3}$ Sus aportaciones económicas fundamentales se encuentran en el capítulo V de su Ética nicomaquea y en los capítulos I y III de su Política. Son aportaciones que se enmarcan en las obras que dedica a cómo puede el hombre vivir bien y llegar a su fin, la felicidad, por medio de las virtudes (Ética a Nicómaco), y cuál es el contexto en el que lo hace de forma natural, la comunidad y la vida política (Política).
} 
primera" (Aristóteles, 1990, pp.2 y 19). Esta apertura a la realidad, junto con la elaboración previa de una teoría sobre el hombre, sus fines y su proyección social y política, le sirven a Aristóteles como instrumentos de análisis causal y teleológico, permitiéndole emitir juicios de valor de las distintas actividades económicas que caen dentro de sus consideraciones (Schumpeter, 1995, pp. 93 y 101).

Los hombres no se asocian solo para darse mutuo socorro, ni para defenderse de los ataques, ni para las transacciones comerciales. No se asocian solo para vivir, sino para vivir bien (Aristóteles, 1981, pp.138-140). "La ciudad es una asociación de familias para una vida perfecta y autosuficiente, y esta es, como decimos, la vida buena y feliz.... Hay que concluir, por tanto, que la comunidad ciudadana tiene por objeto las buenas acciones y no solo la vida en común" (Ibídem, 140). La oikonomia, como respuesta a la preocupación por atender las necesidades de la vida, o incluso el comercio, no perfecciona la ciudad por sí sola. Aristóteles critica incluso a aquellos gobiernos que se conforman con este mínimo, "porque es muy fácil confundir los medios con los fines cuando éstos se pierden de vista y, como consecuencia, lo útil cobra cada vez más importancia" (Gómez, 2000, p. 36).

En la concepción aristotélica de la oikonomia, la naturaleza, la razón y la justicia en una comunidad son puntos de referencia ineludibles pues, lo que en el fondo está en juego también a través de una actividad económica y crematística, es una forma de entender y orientar la vida humana (Conill, 2004, pp. 14 y ss.). Desde esta idea de economía de inspiración aristotélica, como arte adquisitivo y de uso de lo que es indispensable para la vida y útil a la comunidad (Aristóteles, 1981, pp. 59-61), se ha llegado a afirmar que la economía no es tanto una técnica sino una praxis humana y como tal en ella se produce una estimación del objeto usado así como de los fines intermedios (Crespo, 2005, p. 296) .

Aristóteles concibe al hombre como ser para el cual existe una forma de vida que le es propia conforme a lo que entiende por naturaleza humana (Spiegel, 2004, p. 25). Según ese proyecto de vida, afirma la existencia de una jerarquía de los

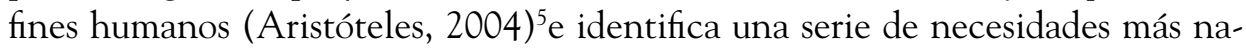
turales que otras cuya satisfacción es necesaria pero no suficiente para alcanzar ese ideal de vida del hombre como ser social y político. En su análisis de las actividades de producción e intercambio no deja de referirse a cuestiones coherentes

${ }^{4} \mathrm{El}$ autor realiza un análisis de la concepción antropológica subyacente en las aportaciones neoclásicas y de la escuela austriaca y finalmente propone como herramienta de contraste un referente antropológico a partir de las aportaciones de Aristóteles en este campo.

${ }^{5}$ Aristóteles dedica el primer libro de su Ética nicomaquea a indagar cual es el fin de las acciones humanas, porque una vez entendido el fin, es más fácil buscar los medios. También reconoce que lo más peligroso es errar en el fin, pues errado este, no pueden ir los medios acertados. Aristóteles concluye que el fin de las acciones humanas es la felicidad y que la verdadera felicidad consiste en actuar conforme a la recta razón, en lo que consiste la virtud. 


\section{Zulema Calderón Corredor}

y relacionadas con ese concepto previo de vida buena, como es la cuestión de la virtud y el vicio en la valoración de los deseos-preferencias. No parece identificar el comportamiento racional con la persecución de riqueza (Schumpeter, 1995, pp. 101-102) y su valoración "económica" de las actividades adopta un punto de vista global (frente a uno individual o particular), no solo por la incorporación de la perspectiva teleológica especialmente cuando trata de instituciones sociales, sino por la relevancia que para él suscita el juicio de justicia o injusticia en las relaciones humanas. Junto a sus aportaciones en materia de reciprocidad, equivalencia o justicia conmutativa en los intercambios (teoría del valor), fundamenta por ejemplo el derecho de propiedad en la posibilidad que ofrece para la práctica de la filantropía a través del ejercicio de las virtudes de la templanza y de la generosidad (Spiegel, 2004, p. 29).

En la acción humana económica que se desprende de sus aportaciones están contenidas todas las libertades propias del hombre que éste pone en juego: las innatas (entendimiento, voluntad como apertura a todo bien, libre arbitrio como dominio de los propios actos por parte de la voluntad) y las adquiridas (libertad como autodominio derivado de la adquisición de virtudes y libertad política) (Crespo, 2005, pp. 296 y ss). La acción económica es considerada como un acto de libertad moral.

\subsection{Economía y eficiencia en la doctrina escolástica}

Las aportaciones al análisis económico de los doctores escolásticos han sido clasificadas por Schumpeter (1995, pp.111-136) dentro de tres periodos que comprenden desde el siglo IX al XVII. El primer periodo llega hasta el siglo XII con Eriúgena, Abelardo, San Anselmo y Juan de Salisbury, un grupo de pensadores especialmente atraídos por problemas epistemológicos. El segundo periodo se desarrolla en el siglo XIII, con la consolidación del sistema de pensamiento llamado clásico y aportaciones de la escuela franciscana (Grosseteste, Alejandro de Ales, San Buenaventura, Duns Escoto) y dominica (San Alberto Magno y Santo Tomás, especialmente). A ello contribuyó el redescubrimiento de los escritos de Aristóteles, lo cual les facilitó buena parte de la tarea que tenían por delante, no solo en metafísica sino en el campo de las ciencias sociales y físicas. La influencia del Estagirita en la escolástica por medio de la síntesis aportada por Santo Tomás es evidente, especialmente en cuestiones relacionadas con el intercambio de bienes, la teoría del valor y el interés.

\footnotetext{
${ }^{6}$ Nota 18. El autor aplaude al filósofo por haberse negado a identificar precisamente el comportamiento racional con la persecución de la riqueza. No obstante también le critica por no seguir en cuestiones económicas una metodología de análisis y contrastación previa a la emisión de juicios de valor, tal y como sí hace en cuestiones políticas.
} 
Finalmente, el periodo que va desde el siglo XIV hasta el XVII (con Buridián, Oresme, San Antonio de Florencia, Lesio, Molina, Mercado, Lugo, etc.) comprende prácticamente toda la historia de la economía escolástica, refleja en gran medida todo el fenómeno del capitalismo naciente y representa el nacimiento de la llamada Economía "científica". La llamada Escuela de Salamanca en España pertenece a este último periodo.

La disciplina económica se gestó en sus aportaciones formando parte de la Teología Moral pues, de hecho, la atención de los escolásticos se centró en cuestiones que guardaban alguna relación con el ámbito ético o moral, incluyendo las económicas. Así, la idea de lo injusto, tanto en política económica como en la práctica mercantil, iba unida a la idea de contrario al bienestar público. La jurisprudencia escolástica, básicamente centrada en cuestiones puntuales, nunca trató de un modo sustantivo la economía en su conjunto o como un cuerpo unitario de problemas. Será a partir del tercer periodo (siglo XIV al XVII) cuando los doctores tratarán los distintos fenómenos del capitalismo naciente, sirviendo sus aportaciones de base para el trabajo analítico posterior (Schumpeter, 1995, p. 133 $)^{7}$. La cuestión de la usura y de las condiciones para que el cobro de interés fuera moralmente admitido, la justicia en la fijación de los precios (precios de mercado o legalmente establecidos), la teoría del valor o la moralidad del comercio eran temas constantes de su atención (Rothbard, 1999, p.133) ${ }^{8}$. El comercio, calificado como actividad moralmente neutral, queda legitimado por sus fines, como por ejemplo la búsqueda del propio sustento, la caridad o la prestación de un servicio público (Spiegel, 2004, p. 60). Aparece de nuevo configurado el acto económico como un acto de libertad moral.

Las referencias explícitas a la cuestión de la eficiencia económica se pueden encontrar especialmente en la doctrina económica escolástica relativa al papel del "empresario". S. Bernardino de Siena, por ejemplo, se refiere a la eficiencia (o diligencia) como una de las cuatro cualidades para tener éxito, entendiendo por tal el estar bien informado de los precios, costes, cualidades del producto y ser sutil al ponderar riesgos y oportunidades de beneficio (Rothbard, 1999, p.114). No obstante, una valoración positiva en términos de justicia implicaba una va-

\footnotetext{
${ }^{7}$ Schumpeter menciona dentro de los desarrollos escolásticos de Economía aplicada el concepto de bien público concebido en su opinión de forma utilitarista con referencia a la satisfacción de las necesidades económicas percibidas por la razón o ratio recta del observador. En ello Schumpeter identifica el concepto de bienestar propio del Welfare Economics de Pigou aunque tampoco explica si el bienestar de los escolásticos coincidía o no con el simple "estar bien" de Aristóteles y por tanto como condición necesaria pero no suficiente de la vida buena a la que el mismo se refiere. Si la escolástica seguía en estas cuestiones a Aristóteles es de suponer que también sobre ellos tuvo influencia su teoría sobre la vida buena y el lugar que en la misma ocupa la utilidad o el bienestar.

${ }^{8}$ Así por ejemplo Francisco de Vitoria, dentro de la Escuela de Salamanca y aunque sus contribuciones económicas son modestas en extensión, muestra su interés por la moralidad del comercio y la justicia en la fijación de los precios.
} 
loración positiva en términos de competitividad, de ahí que la doctrina en torno al precio justo-competitivo en realidad comprendiera ambos aspectos (justicia y eficiencia) de una misma realidad.

En general, puede decirse que en muchas cuestiones la escolástica representó una continuidad respecto a las aportaciones de Aristóteles en este campo (Schumpeter, 1995, p. 127) y que las motivaciones de los doctores, principalmente de origen normativo, guardaban cierto paralelismo con los juicios de valor aristotélicos respecto de la vida buena. El tratamiento que Santo Tomás propone acerca de la administración de la propiedad privada, desde la defensa de su uso abierto al provecho de otros, la generosidad, la liberalidad y la caridad (Spiegel, 2004, p. 58), recuerda al hombre social de la Ética. A este respecto Schumpeter (1995, p. 141) reconoce que el motivo del análisis escolástico no fue la curiosidad científica sino el deseo de entender algo que estaban llamados a juzgar desde un punto de vista moral, es decir, el mérito o el demérito de la conducta individual en el marco de unas instituciones y condiciones dadas.

Lógicamente, ese ejercicio de contraste debía contar con una medida de referencia más allá de la norma que además sirviera a la misma de fundamento. Una realidad, si se quiere, que aportara el criterio de comparación, pues las aportaciones escolásticas en materia económica estaban insertas en una metafísica o filosofía que llevaba siglos preguntándose por el ser y la esencia de las distintas realidades. Conforme al esquema de las disciplinas filosóficas de Santo Tomás, además del orden de la naturaleza (objeto de la Física, la Matemática y la Metafísica) y del orden del pensamiento (objeto de la Lógica), existía el orden de los actos de voluntad, producido por el hombre, el orden moral, objeto de la Filosofía Moral o Ética. En sus dimensiones colectivas este orden es estudiado también por la ciencia del Estado, la Economía y la Política (Marías, J. 1981, p.164).

Las aportaciones anteriores al pensamiento económico convivieron desde el S. XIV con el nominalismo ockhamita, cuya influencia será fundamental en la antropología económica posterior de referencia debido a sus efectos en cuestiones éticas. Es decir, el nominalismo negaba el poder de la razón humana para llegar a las verdades esenciales sobre el hombre y sobre el universo y por tanto ponía en duda la posibilidad de llegar a una ética sistemática para el hombre. En este sentido puede decirse que el nominalismo "preparó el camino para el escepticismo y positivismo modernos" (Rothbard, 1999, p. 103). No obstante, a pesar de la influencia nominalista, la ética económica del pensamiento aristotélico-tomista sigue vigente en las aportaciones doctrinales importantes (Truyol y Serra, 2004, p. 435). Será precisamente la reacción ante tales posiciones ético-religiosas la que lleve a protestantes fuera de la Iglesia católica por un lado y a secularistas y racionalistas por otro, a oponerse y a atacar las aportaciones escolásticas. Rothbard (1999, p. 163) se refiere a esta circunstancia y de nuevo a cómo la actitud epistemológica cambió profundamente. En efecto, en el S. XVII, “dos filósofos de 
orientación dispar obraron en conjunción la fatal escisión de lo racional y lo empírico que ha impregnado el método científico hasta nuestros días: el inglés $\mathrm{F}$. Bacon (1561-1626) y el francés R. Descartes (1596-1650)", habiendo estado hasta entonces razón y experiencia integradas con el tomismo y el método escolástico.

\section{ESTADO ABSOLUTO Y UTILITARISMO: DEL MERCANTILISMO A LA ECONOMÍA CLÁSICA}

Aunque el análisis histórico ha situado el embrión del estado moderno hacia el siglo XIII (Strayer, 1970, p.58), no será hasta el XVI cuando se inicie su consolidación (Tilly, 1975, p. 27), siendo lo económico un factor al servicio de los distintos grupos de poder. A ello contribuyó el paulatino abandono de la doctrina escolástica del derecho natural como referente de legitimación y control al poder político. Al mismo tiempo comenzó un proceso de ruptura que, enraizándose en posturas epistemológicas recelosas con nuestra capacidad de conocer, facilitó el vuelco antropológico individualista y la huida de los fines en la concepción del hombre.

El racionalismo, tanto desde la perspectiva cartesiana como desde el empirismo, facilitó la entrada del criterio utilitario en el análisis del tratamiento de las cuestiones sociales, jurídicas y económicas. De hecho, las consecuencias de este enfoque utilitarista sobre el área económica y con ello sobre la eficiencia, fueron determinantes para entender sus desarrollos posteriores.

\subsection{El mercantilismo: del juicio moral al juicio estatal}

El absolutismo estatal, ya consolidado en el siglo XVI, precisaba para su mantenimiento no solo de estructuras estables de ingresos públicos sino de la creación de alianzas entre los distintos estratos del poder, también del económico. Como consecuencia de ello se generó un "sistema de privilegio estatal sistemático", especialmente para subsidiar las exportaciones y restringir las importaciones así como para conceder monopolios privilegiando a unos a costa de los competidores y de los consumidores, todo ello para constituir lo que se ha denominado un "capitalismo monopolista de Estado" (Rothbard, 1999, p. 247).

La desaparición de los límites externos al ejercicio del poder estatal estuvo acompañada de la desaparición de criterios exteriores al intercambio económico, más allá del afán de lucro de alguna de las partes implicadas y desde la connivencia del poder político. Las implicaciones en materia de intercambio que se derivaron del mercantilismo no resultaban compatibles ni con las teorías escolásticas todavía vigentes acerca de la formación del precio justo-competitivo ni con las de la necesidad y utilidad como determinantes del mismo, ni con la aceptación del 
mutuo beneficio de las partes intervinientes (Schumpeter, 1995, p.138). Tanto la cuestión de la justicia como la de la eficiencia económica resultaron subordinadas al interés político y al afán de lucro individual.

\subsection{Hacia la economía clásica: racionalidad y utilitarismo}

Conforme avanza la Modernidad ${ }^{9}$, el racionalismo, el utilitarismo y la acentuación del individualismo en las teorías político-sociales, van propiciando la adopción de métodos de trabajo y análisis que influirán en el modelo antropológico para el estudio de la acción humana económica.

Desde el siglo XVII, y especialmente desde la Ilustración, se generaliza una visión racionalista del hombre en la que lo intelectivo y lo sensitivo se encuentran separados. Es decir, la acción humana se concibe como resultado de una operación racional y abstracta, consecuencia de aplicar una serie de reglas automáticas de carácter formal. Se prescinde en gran medida de la influencia de lo corporal y lo sensible en la vida del hombre así como del carácter contingente y cambiante que de ello se deriva. Esta visión parcial es consecuencia de la pretensión de lograr un conocimiento certero y controlable sobre el hombre en el sentido en que lo habían hecho las ciencias de la naturaleza. Esta antropología parcial e incompleta dificulta la comprensión del sentido de la acción humana y la elaboración de una teoría razonable de la acción económica (Martínez-Echevarría y Ortega, 2005, p. 514).

Trasladado al orden social (Martínez-Echevarría y Ortega, 2005, pp. 51-533), la concepción racionalista de la ley natural termina identificándola con un principio de orden global que se impone de modo necesario e inevitable y que actuaría en forma de "mano invisible", llevando al logro del orden social con independencia de las motivaciones de cada uno. La ley natural dejaría así de ser un principio vital operativo. El resultado es un diseño dualista de la acción humana pues en este marco la libertad solo puede ser entendida como puro arbitrio, haciendo de la compatibilidad entre libertad y orden un problema irresoluble. Su traducción en la vida político-económica consiste en que ésta es concebida como una esfera autónoma e independiente de toda regulación moral o religiosa, sin subordinación a un principio superior (Millán, 1976, pp. 230 y ss).

El utilitarismo, por su parte, se gestó especialmente en el S. XVIII y proyectó su influencia en los métodos e hipótesis de trabajo de las ciencias sociales de aquel momento y de los siglos posteriores. Es interesante conocer cuáles fueron sus raíces intelectuales y qué papel jugó en ellas la perspectiva ética.

\footnotetext{
${ }^{9}$ La palabra "Modernidad" tiene connotaciones filosóficas e ideológicas y describe asimismo una actitud mental que llega a ser dominante durante la Edad Moderna pero que no se circunscribe a ese periodo de la Historia. Ha sido definida como un intento de explicación, coherente y sistemático del mundo, del hombre, de Dios y de su historia.
} 
Durante el S. XVIII buena parte de la doctrina (Condillac, Hume, Hartley) recurre a la psicología para explicar comportamientos individuales, de grupo y hechos sociales objeto de estudio, sin plantearse su relación con cuestiones no psicológicas. Simultáneamente se potencia el desarrollo de una ética de carácter analítico que no se mezcla con la finalidad normativa en el análisis del comportamiento real. De la misma forma que en estética la estimación subjetiva de una obra de arte será la que produce su valor objetivo, salvo por ciertos matices, pasa a ocurrir lo mismo en el campo de la ética (Shartesbury, Hutchenson, Hume, Alison) (Schumpeter, 1995, pp. 165 y ss) ${ }^{10}$. Es decir, las estimaciones subjetivas sobre el comportamiento humano que adquirieron entonces relevancia, (hipótesis de Hobbes acerca del egoísmo individual y hedonista como factor determinante de la conducta humana, hipótesis de Bentham sobre la prioridad del propio interés, hipótesis de Helvetius sobre el propio interés cómo equivalente en lo social a la ley de gravitación en lo físico, acentuación de la racionalidad del comportamiento, etc.) favorecen la creación de un tipo moral objetivo, el del egoísta amable. Este modelo humano, sereno y despreocupado, busca activamente el placer y la satisfacción de sus deseos individuales hasta convertirlos en su finalidad última y en motivo de acción universal (Hume, A. Tucker).

De esta forma, habiendo la razón eliminado todos los valores supra-personales con excepción del bien de la sociedad, "¿en qué podía consistir ese bien de la sociedad sino en la suma total de todas las satisfacciones que los individuos obtienen de la realización de los esquemas hedonísticos de referencia?"(Schumpeter, 1995, p.169). Los fines de la acción humana y las referencias a la "vida buena" son sustituidos por este canon fundamental de la ética utilitarista en la valoración de la acción económica, siendo el consecuencialismo dónde se aprecia la escisión entre moralidad y felicidad (Spaemann, 1991, p. 208). Con la ampliación de posibilidades para la acción humana se rechaza la eudaimonia (felicidad, vida lograda) como principio del que puedan derivarse reglas capaces de guiar la acción. Con ello, el bien común o utilidad social de los doctores escolásticos se polarizó en la suma de placeres y dolores individuales como únicas realidades últimas en un modelo antropológico estable y simplificado (Schumpeter, 1995, p.171). La diferencia de este enfoque con el de los escolásticos está en que estos limitaban el punto de vista utilitarista a la actividad puramente utilitaria "mientras que los utilitaristas redujeron el entero mundo de los valores humanos a ese esquema,

\footnotetext{
${ }^{10}$ En su opinión, la psicología usada fue siempre psicología individual, introspectiva, pocas veces dotada de hipótesis sobre las reacciones individuales. "Los valores estéticos y éticos se explicaban, pues, de un modo que recuerda el utilizado por los economistas franceses e italianos del siglo XVIII y por la mayoría de los economistas de todos los países en el siglo XIX para explicar los valores económicos. Este procedimiento se llamaba empírico... No tenía nada de "experimental" ni inductivo, y en realidad no era muy realista...".
} 
eliminando, como contrario a la razón, todo lo que realmente importa al hombre" (Schumpeter, 1995, p. 173) ${ }^{11}$.

La aproximación individualista se irá insertando en las metodologías de estudio e irá condicionando la mirada de la ciencia económica y con ello su consideración de la eficiencia. El análisis económico de grupos y clases de individuos, siendo fundamental en la economía clásica, se va desviando paulatinamente hacia el individuo como centro del análisis hasta consolidarse a partir del marginalismo. No se trata ésta de una característica cualquiera dado que "la aceptación del individualismo metodológico y la racionalidad han sido el soporte de la mayor parte de las aportaciones de Teoría Económica” (Romero, 2003, p. 23).

\subsection{La eficiencia en la economía clásica}

Teniendo en perspectiva los efectos del mercantilismo, así como los distintos elementos que van influyendo en los métodos de las ciencias sociales (psicologismo, racionalismo, utilitarismo, subjetivismo ético e individualismo), resulta más fácil poner en contexto las aportaciones doctrinales que sentarían las bases de la economía clásica primero y de la neoclásica después.

Además de la obra de Smith, los Principios de economía política y tributación de D. Ricardo (1814) y los Principios de economía política de J. S. Mill (1848) son consideradas las obras de referencia de la economía clásica. Estos autores centraron su interés en analizar qué propiedades del trabajo, del intercambio y del mercado favorecían la generación de riqueza, crecimiento y desarrollo. Aunque no destaca entre sus aportaciones una definición explícita de la eficiencia económica como criterio de medición asignativa, en la producción o en el consumo, sí identifican distintas propiedades de la acción humana o del intercambio que resultan eficientes por sus resultados.

Las propiedades de coordinación económica espontánea de la "mano invisible" (Smith, 1994, p. 554) o su antecedente próximo con La fábula de las abejas (o los vicios privados hacen la prosperidad pública) de B. Mandeville (1670-1733), recuerdan al diseño dualista-determinista de la acción humana que antes señalábamos para el ámbito social. A. Smith, como reacción frente a los postulados mercantilistas, identifica en la tendencia individual a buscar el propio interés (Spiegel, 2004, pp. 225-226) y en el contexto de librecambio (Spiegel, 2004, p. 255) la fuerza motora del resultado eficiente del mercado (efectiva satisfacción de las necesidades) o la consecución del interés o bien público. Con ello consigue el mismo objetivo del que partía Aristóteles, la satisfacción de las necesidades de la vida, aunque elimina del acto económico toda estimación global del fin (vida

\footnotetext{
${ }^{11}$ Analizando la utilidad de las hipótesis utilitaristas en distintos ámbitos del análisis económico afirma que se trata de hipótesis contraproducentes en el caso de cuestiones que impliquen el análisis de esquemas reales de motivación.
} 
buena) para centrarlo en un fin particular: maximización de la utilidad individual. La competitividad, entendida como libre concurrencia de esfuerzos individuales que buscan el propio interés, permite la mejor satisfacción posible de las necesidades (propias y ajenas), pudiendo calificar las circunstancias que favorecen este resultado, así como el resultado mismo, como de eficientes (Alcón, 1994, p.363 $)^{12}$. El acto humano deja de ser un acto en el que se ponen en juego todas las capacidades de valoración y elección características de un acto de libertad moral.

Aunque se ha discutido si el sistema de coordinación que describe A. Smith se asienta en un enfoque dual conforme al cual las relaciones sociales estarían gobernadas por los sentimientos morales (simpatía y altruismo) y las económicas por el egoísmo o por el contrario ambas esferas se encontrarían interconectadas (Fernández y Prieto, 2004, pp. 10 y ss), lo cierto es que la búsqueda del propio interés ha prevalecido como clave explicativa en los modelos económicos sobre los que se desarrollará la Economía durante los siglos siguientes. Pueden encontrarse referencias explícitas (Orduna, 2008 y Ratzinguer, 1985) al proceso de separación histórica del sistema de pensamiento económico respecto de la sociedad, su cultura y sus valores, es decir, entre los condicionamientos económicos de mercado o la competitividad, y "las exigencias de una común concepción simbólica del mundo y del comportamiento" (Koslowski, 1989, p. 9).

Por su parte, quien verdaderamente tiene para algunos el honor de ser el "padre de la Economía moderna”, R. Cantillón (1680-1734), ostenta tal título entre otras cosas por haber emancipado su análisis económico de su anterior subordinación a cuestiones éticas (escolástica) y políticas (mercantilismo). Puede que fuera para escapar de la "ciénaga mercantilista" pero lo cierto es que Cantillón centró sus análisis en la dimensión económica de la acción humana abstrayéndola, aunque fuera temporalmente, de otras dimensiones por muy importantes que éstas fueran (Rothbard, 1999, pp.388-389).

J.S. Mill (1806-1873) seguirá muy de cerca las ideas ya analizadas acerca del utilitarismo y partirá de un concepto de libertad como ausencia de obstáculos externos con el límite del perjuicio al prójimo. Formalizará el modelo antropológico de referencia bajo el concepto homo oeconomicus en su On The Definition of Political Economy and The Method of Investigation Proper to It, publicado en 1836.

La consideración del acto económico como acto moralmente neutral quedará acentuado desde el momento en que la felicidad se vaya paulatinamente identi-

\footnotetext{
${ }^{12}$ Dentro del sistema de libertad natural que concibe Smith, los objetivos sociales no tienen que estar previamente establecidos sino que son, junto al crecimiento económico, el resultado espontáneo de la diligencia y del interés de los individuos que componen la sociedad. El bienestar social y la libertad individual son presentados en una relación armónica dentro de un sistema dirigido exclusivamente por reglas de justicia que protegen al individuo y constituyen el marco propio para las relaciones espontáneas. En este sentido la eficiencia, entendida como la satisfacción de las necesidades humanas de la mejor de las maneras, sería posible gracias a una condición previa de justicia en al ámbito social y económico.
} 
ficando con la satisfacción de las necesidades materiales y con el bienestar físico. La eficiencia económica, si bien se sigue considerando desde la consecución de un objetivo de trascendencia social, al fundamentarse en la racionalidad como búsqueda del interés individual, derivará en la paulatina separación entre el bien personal y el bien común, como refleja la sustitución de la idea de bien común (en el que se participa) por la de suma de placeres y dolores ya apuntada (como mera adición o sustracción). Por ello se afirma (Pérez de Ayala, 1976, p. CCCV) que el utilitarismo en al ámbito económico supone un rechazo frontal a la idea de bien común inherente a todo concepto de equilibrio económico en la sociedad.

Ese bienestar personal contará por única referencia con la individual apreciación de lo que es bueno (útil, más bien) para uno mismo, sin que exista un lugar para la consideración del fin (compartido) de la vida humana, en su aspecto personal o comunitario. Al no haber una idea clara del thelos como algo propio de la persona, predominan los bienes de la eficacia sobre los de la excelencia. Es por ello que el liberalismo separa necesariamente el concepto de efectividad o de ventaja, del relato de las virtudes o excelencias (MacIntyre, 1994, p. 119).

\section{ESTADO BENEFACTOR Y POSITIVISMO CIENTÍFICO: DE LA ECONOMÍA CLÁSICA AL KEYNESIANISMO}

A partir de 1870 podemos identificar una ruptura en el pensamiento económico como reacción ante las aportaciones de la escuela clásica, con el desarrollo marginalista primero y la elaboración de la teoría del valor después. En estos años se asentarán las bases de la corriente ortodoxa por excelencia en materia económica, la economía neoclásica, un término un tanto impreciso pero que agrupa un conjunto de aportaciones cuyos referentes antropológicos analizaremos seguidamente.

Desde D. Ricardo comienza a desarrollarse en la Teoría Económica, a diferencia de A. Smith, una tendencia cientificista que se consolida en la economía neoclásica y dura hasta hoy. La acción económica es considerada desde su racionalidad estratégica o instrumental, sus agentes vistos desde la exclusiva perspectiva del homo oeconomicus y el sector económico de la actividad humana es tratado de forma segmentada prescindiendo de analizar otras interrelaciones humanas esenciales (Ureña, 1994, p. 74). Puede describirse también como un "redescubrimiento del hombre en las ciencias", un "desplazamiento del paradigma científico de la naturaleza inanimada del fisicalismo hacia una ciencia que incluye en praxis científica misma al sujeto de la ciencia, el hombre" (Koslowski, 1989, p. 7).

Como Schumpeter reconoce al describir el marco intelectual del periodo (1995, p 471), resulta destacable por la importancia que tuvo entre los economistas la influencia de A. Comte, cuyos antecedentes pueden vincularse con la tradición cartesiana, el empirismo inglés y la filosofía escocesa del sentido común. 
Su influencia en la Economía ha sido considerable, especialmente en materia metodológica, pues tras acusar a los economistas clásicos de especulación acientífica, abogó por utilizar los métodos de las ciencias físicas. Esta preocupación por otorgarle a la investigación económica el apelativo de científica y la identificación de lo científico con la verificación experimental de las proposiciones, llevó paulatinamente no solo a distinguir el análisis de los hechos de las proposiciones normativas, sino a excluir de estas últimas su carácter científico.

Aunque fueron distintos los factores que suscitaron la ruptura con la tradición clásica (Schumpeter, 1995, p 836) ) $^{13}$, la tendencia epistemológica hacia el cientificismo y la gestación del Estado benefactor, generaron entre los economistas un nuevo interés no solo por otorgar mayor rigurosidad a los desarrollos analíticos, sino por los incipientes movimientos de reforma social. Ello, unido a las innovadoras aportaciones en torno a la teoría del valor y la medición de la utilidad, determinaron el desarrollo de este proceso de ruptura y de integración de aportaciones.

Más adelante, ya entrando en el siglo XX, serán las particulares circunstancias económicas y sociales motivadas por la Primera Guerra Mundial las que determinen la generación de nuevos trabajos que complementen las aportaciones anteriores desde la perspectiva keynesiana.

\subsection{Positivismo científico, formalización e individualismo metodológico: el marginalismo y la escuela neoclásica}

En relación a los antecedentes de esta nueva etapa del análisis económico, pueden situarse ya en el periodo anterior algunos intentos de matematización por parte de A. Cournot (1801-1877), quien inspirado por el racionalismo de la tradición filosófica francesa, confiaba en los poderes de la razón para descubrir el orden matemático vigente en el mundo (Spiegel, 2004, p.509). No obstante, es en torno a 1870 cuando se sitúan tres aportaciones económicas de gran importancia que sentarían las bases para el posterior trabajo analítico de la acción económica y del concepto económico de eficiencia: las de S. Jevons en Inglaterra (1835-1882), C. Menger en Austria (1840-1921) y L. Walras en Francia (1840-1921). Sus aportaciones, concurrentes en la idea de la utilidad marginal y del principio de "disminución marginal de la utilidad" ante incrementos en el consumo, son consecuencia de esa focalización en el análisis del comportamiento individual ya comentada. La teoría de la utilidad marginal o también denominada Teoría subjetiva del valor, responde a la inquietud de conocer lo que determina el valor de los bienes y con ello su precio y demanda. Conforme a esta teoría, dicho valor depende de la utilidad o beneficio que de forma individual y subjetiva se atribuya a cada bien conforme a las necesida-

\footnotetext{
${ }^{13} \mathrm{~A}$ finales del siglo XIX el liberalismo económico, las virtudes del laissez-faire y el liberalismo político empiezan a ponerse claramente en cuestión y perder atractivo para el electorado.
} 
des existentes en un momento dado, lo cual hace del mismo una magnitud variable (a diferencia de lo mantenido por los clásicos) y por tanto decreciente a medida que las necesidades son objeto de satisfacción (utilidad marginal decreciente).

Las aportaciones del marginalismo en materia de procesos de asignación de recursos son fundamentales en relación a la configuración posterior del concepto de eficiencia y representan una continuidad en el enfoque filosófico utilitarista que identifica la moral con la elección racional de los individuos egoístas. Su interés se centra temporalmente en el corto plazo, a diferencia de la tendencia de los clásicos a poner la mirada en el crecimiento económico a largo.

Los intentos de integrar este análisis marginalista con algunas de las aportaciones de la economía clásica, especialmente por parte de A. Marshall y sus seguidores $^{14}$, derivaron en lo que se ha denominado economía neoclásica o escuela neoclásica, sistema de pensamiento económico que se ha convertido en la corriente ortodoxa o dominante en materia económica.

En este sistema los individuos persiguen sus propios fines y sus acciones se coordinan y ajustan mediante sus propias respuestas a las señales de los precios formados en el mercado. La ausencia de coacción externa permite una coordinación no deliberada que conduce al equilibrio general. Se trata de un sistema estático, cerrado y determinista que recuerda al mundo de la física natural. En Jevons, Walras, Pareto, Samuelson y Hicks pueden identificarse claras influencias de la teoría energética de la física y de la termodinámica. "El espíritu neoclásico es el de una ciencia que pretende, por ser exacta, reducir todas las variables a datos accesibles" (Crespo, 2005, p. 278).

La base axiomática del modelo es la idea de escasez, y ello, unido a su falta de pronunciamiento sobre los fines, convierte a la Economía en la ciencia de la elección, en la ciencia de los procesos asignativos.

La Economía se configura como ciencia de los puros medios olvidando el hecho de que el hombre es un ser ontológicamente abierto a una pluralidad de fines que no le resultan neutrales. El modelo toma los fines, los motivos y las preferencias como dados y solo acepta consideraciones respecto de los medios. La aceptación de los fines como dados y constantes hace prescindible la intervención de la Ética, fenómeno que encuentra su explicación en tres elementos que se han venido anticipando: el elemento axiológico, al identificar el afán de lucro con la virtud, el epistemológico, por la prevalencia de la formalización y las categorías cuantitativas y el institucional, con el desarrollo del fenómeno de la mediación en favor de mecanismos de decisión colectivos (Conill, 2004, pp. 114 y ss.).

Lo que podría denominarse "polivalencia teleológica de la Teoría Económica” (Gómez Fernández, 1992, p. 28) es asimismo resultado de su esfuerzo por

\footnotetext{
${ }^{14}$ Otros autores neoclásicos contemporáneos de Marshall son el sueco Knut Wicksell (1851-1926), el norteamericano Irving Fisher (1867-1947), el inglés Arthur Pigou (1877-1959) y el italiano Vilfredo Pareto (1848-1923).
} 
acumular explicaciones relativas a la realidad sin la pretensión de lograr transformaciones dirigidas a su perfeccionamiento. Esta situación, en palabras de L. Orduna (2008, pp. 12-13), dejaría a la ciencia vacía de sus fines últimos, siendo el tipo de conocimiento al que se refiere la Economía necesariamente de orden finalista. Lógicamente este vacío teleológico tendrá sus consecuencias tanto en la definición del concepto de eficiencia (¿eficiencia para lograr qué?) como en su medición (¿qué medios de entre los posibles se consideran?).

El postulado de racionalidad neoclásico acerca del agente ha sido también objeto de crítica (Simons, 1978). Es decir, las leyes económicas que rigen la acción de los agentes no solo dependen del principio de comportamiento económico, sino también de otras notas antropológicas, por lo que carece de todo fundamento "entender que el principio de comportamiento económico constituye la base de los modelos de la Teoría Económica moderna” (Rubio, 1999, p. 339).

La teoría de juegos y la teoría de juegos evolutivos en particular, también desafían el fundamento de racionalidad del homo oeconomicus (Calsamiglia, 1988 y Zamagni, 2006). Individuos que responden a este modelo, racionales y egoístas, consiguen peores resultados que si hubieran cooperado, evidenciando algunas de las investigaciones cómo no necesariamente los comportamientos racionales en sentido pleno son los que aseguran a los jugadores la máxima ganancia ${ }^{15}$.

Antropológicamente el agente neoclásico tiene solo tendencias sensibles, ilimitadas e insaciables y la acción humana se hace impersonal, sin posibilidad de historia e incompatible con el carácter libre de la acción humana (MartínezEchevarría, 2005; Negro, 2008, p. 15). Sin embargo, en realidad, las acciones derivan su carácter en tanto que son parte de conjuntos más amplios, es decir, la vida es algo más que una secuencia de acciones y episodios individuales (MacIntyre, 2009, p. 252), lo que confiere a la noción de historia tanta importancia como a la misma acción. El modelo neoclásico es útil para explicar situaciones en las que solo operan motivaciones extrínsecas, no hay aprendizaje, los factores son perfectamente sustituibles, y no son relevantes las interacciones que tienen lugar entre las personas dentro del sistema (Argandoña, 1994; Conill, 2004).

Rubio de Urquía también se refiere a las limitaciones derivadas del modelo de agente neoclásico (1993; 1993a; 1994), el cual, no es que delimite el campo específico de lo asignativo, sino que deja fuera muchos procesos económicos y singularmente los más importantes de entre ellos. En su opinión, se trata de una caracterización antropológica que "excluye casi todos los rasgos esenciales definitorios de la persona y la acción humana en su complejidad real”(Rubio, 1993, p.78). Es decir, el

\footnotetext{
${ }^{15}$ Comenta Zamagni que en el ámbito de la teoría de juegos se ha comprobado que la racionalidad no implica que ante las mismas situaciones se hagan las mismas cosas o se adopten las mismas decisiones. "El hecho es que el ambiente en que se desarrolla el juego y las relaciones que se instauran entre ambiente y jugadores son elementos de vital importancia a efectos de la decisión, elementos estos que no abarca el principio de racionalidad", p. 53.
} 


\section{Zulema Calderón Corredor}

proceso asignativo neoclásico, con una caracterización muy concreta del agente, su medio de operación, el conjunto de medios escasos y fines alternativos y la adopción de un principio teórico económico fundamental, el principio económico optimizador, configura leyes económicas que son válidas de forma absoluta o parcial o completamente inválidas para otros tipos de procesos asignativos (Rubio, 1993, p. 77).

Las críticas ya apuntadas al modelo antropológico "neoclásico" recuerdan bastante a las críticas que realiza MacIntyre al modelo antropológico del liberalismo, su inmediato antecedente y para él expresión máxima de la Modernidad (García, 2004, pp. 88 y ss). En su opinión, la concepción del yo inherente al mismo carece de la unidad que le atribuía la tradición aristotélica y agustiniana. Se trata de un ser cuya vida está compartimentalizada (procesos estáticos), carece de narrativa vital (medios y fines dados) y de proyecto por descubrir (ausencia de fin, agente como mero optante), para el que resulta difícil concebir un bien que lo sea para él mismo y para su comunidad (ausencia de motivaciones transcendentes), que experimenta una contradicción entre sus deseos y el fin de su vida (preferencias subjetivas) así como una preferencia de los valores de la eficacia frente a los de la excelencia (comportamiento maximizador, solo medios-fines económicamente valorables).

Esta forma de caracterizar al agente económico puede explicarse por el propio modelo de persona que tenían en la cabeza los economistas cuando elaboraban sus aportaciones. Son caracterizaciones que se han convertido en un "instituto de auto-representación de la sociedad por sí misma” (Rubio, 1993a: 301-312), en representaciones de la realidad "suministradas por la ciencia", y con ello en la forma de entender las relaciones entre las personas, de elaborar planes personales de acción y de producir la realidad social histórica (Rubio, 1999, p. 242).

\subsection{Reacción metodológica y antropológica: escuela austriaca de economía}

A finales del siglo XIX, y como contraste ante algunos supuestos metodológicos y antropológicos del agente económico neoclásico, surge una corriente de pensamiento que se separará de la ortodoxia económica y continuará su andadura particular durante el siglo XX, la escuela austriaca ${ }^{16}$.

Este sistema de pensamiento económico supuso una reacción precisamente frente al uso en Economía de las metodologías mecanicistas de las ciencias naturales y del análisis experimental y a favor de los métodos basados en la deducción e introspección. Entre sus autores se produce en general una defensa del apriorismo en Economía, el individualismo metodológico, la desconfianza hacia los agregados económicos, el rechazo por el uso de las matemáticas y la contrastación cuantitativa, y el énfasis otorgado a los procesos de desequilibrio (Romero, 2003, p.28).

\footnotetext{
${ }^{16}$ Pueden citarse entre sus representantes más importantes a C. Menger, V. Mises, F. Hayek, I. Kirzner, L. Lachmann, entre otros.
} 
Desde sus aportaciones se intentó diseñar una teoría económica que fuera compatible con la libertad desde unos presupuestos metodológicos distintos. En Merger aparece ya una idea de acción humana intencional, con expectativas, con rasgos de incertidumbre debidos a la libertad, el tiempo y el error y de ahí sus desarrollos en el ámbito del llamado equilibrio "dinámico". Sin embargo, Merger parece renunciar a esta concepción antropológica más rica en favor de la exactitud de sus conclusiones (Crespo, 2005, p.276) ${ }^{17}$. Los autores que han pertenecido a esta escuela han ido introduciendo la presencia de una idea más realista de libertad, dando cabida a un componente teleológico no determinista en la acción humana económica. No obstante, este enfoque resulta ambiguo o queda coartado en varias ocasiones.

\subsection{Hacia la consolidación del Estado de bienestar: el keynesianismo}

El contexto social y político que acompañó a las tres primeras décadas del siglo XX facilitó y se retroalimentó, proyectándose hacia el futuro, de las aportaciones del economista británico J. M. Keynes (1883-1946) y la escuela que adoptó su nombre, el keynesianismo. En esas aportaciones se recupera la metodología deductiva clásica y neoclásica aunque se rompe con la herencia de esas escuelas, especialmente con la idea de la capacidad de coordinación automática de la economía o de su tendencia natural al equilibrio con pleno empleo de los factores productivos.

Así, por ejemplo, se dejan de utilizar algunos supuestos como la Ley de Say -la oferta crea su propia demanda-, la inexistencia de ciclos, etc., y se generaliza el uso de magnitudes agregadas frente al uso de las individuales. Su punto fundamental de ruptura con el enfoque neoclásico lo representa el papel del sector público, en la producción, los ciclos económicos y el desempleo, lo cual otorga al keynesianismo un papel fundamental en la consolidación del Estado de bienestar en los países occidentales. Es decir, a diferencia de lo que sucede en el modelo neoclásico, la economía aparece en los desarrollos más simplificados de Keynes como un objeto susceptible de control (Rubio, 1989, p. 55).

Junto a estas aportaciones, que son las que más relevancia han tenido en la síntesis neoclásica, lo más innovador e importante contenido en la Teoría General de Keynes es el estudio de los procesos de asignación no neoclásicos. Es decir, el estudio de los procesos de asignación de recursos presididos por el principio del comportamiento optimizador del agente en los que se producen necesariamente situaciones prolongadas de descoordinación, aportaciones que además de su centralidad están referidas a procesos más cercanos a la realidad y actualmente presentes en ella. No obstante, la caracterización del sistema de pensamiento

${ }^{17} \mathrm{El}$ autor realiza un análisis de la concepción antropológica subyacente en los postulados de los distintos exponentes de la escuela austriaca de economía y los compara con los que subyacen en las aportaciones neoclásicas. Lo anterior le lleva a delimitar los distintos conceptos de libertad de referencia en cada uno de los mismos. 


\section{Zulema Calderón Corredor}

keynesiano más difundido e inspirado en su Teoría General, la síntesis neoclásica, no incluye prácticamente nada de sus aportaciones más innovadoras e importantes, el estudio de los procesos de asignación no neoclásicos, quedando con ello lo microeconómico prácticamente eliminado (Rubio, 1989, pp. 55 y ss.).

El hecho de que haya sido la sintesis neoclásica, con mayor aplicación directa a la política económica, la interpretación más difundida de las aportaciones de Keynes, puede encontrar mejor explicación en un contexto en el que el Estado protector se está consolidando como benefactor para pasar a convertirse en Estado de bienestar. Esto es, se trata de un modelo que aporta las herramientas de análisis y la justificación del papel estatal en la economía, lo cual complementa a la teoría vigente sobre el Estado y potencia su desarrollo dentro del itinerario ya recorrido durante la Modernidad. Como ocurriera en al ámbito jurídico, el positivismo científico atribuye un papel económico transcendental al Estado en la tarea de responder a las demandas sociales desde la fuerte influencia que ejerce, también en el ámbito jurídico, el utilitarismo y el consecuencialismo.

\subsection{La eficiencia en la economía neoclásica}

La eficiencia económica como criterio normativo adopta identidad propia con la gestación y el desarrollo de la economía neoclásica. F. Y. Edgeworth (18451926) realizó aportaciones fundamentales al concepto de decisión económica individual y a la eficiencia en el intercambio en las que se reconoce una carga significativa de influencia del utilitarismo (Spiegel, 2004, p.526). Por su parte W. Pareto (1848-1923) incorpora a las condiciones del equilibrio general walrasiano el concepto de "óptimo" en el que la utilidad o bienestar individual ocupa nuevamente un lugar destacado (Spiegel, 2004, p.558).

La eficiencia se evalúa y se mide como objetivo deseable para el consumo, para la producción y para la distribución de bienes. Respecto del consumo la doctrina identifica qué tipo de necesidades existen, cómo deben atenderse para que la satisfacción total sea la máxima posible y cómo medir ese grado de satisfacción conseguido. Respecto de la producción de bienes la eficiencia garantiza el mejor aprovechamiento posible de los recursos o la reducción máxima del coste unitario. La eficiencia económica se constituye así como criterio de bondad en la evaluación económica de la acción humana y de las políticas de intervención pública.

A continuación se apuntan distintos aspectos antropológicos y filosóficos que han ido configurando la formulación del criterio de eficiencia en la economía neoclásica. Este análisis permitirá conocer mejor las limitaciones del marco antropológico que ha acompañado esta configuración y sacar conclusiones acerca de sus consecuencias. 


\subsubsection{La ausencia de fines}

Decíamos antes que la Economía se va configurando como la ciencia de los puros medios sin que la valoración de los fines entre dentro de sus consideraciones. Se puede hablar por tanto de la polivalencia o de la subjetividad de los fines a los que se dirige la acción económica cuya eficiencia se valora.

No obstante, la eficiencia económica, referida a una forma de acción que permite obtener los mejores resultados con el mínimo de medios y esfuerzo a emplear, necesita primero responder a una serie de preguntas previas: para qué, para quién, cómo, dónde..."es preciso conocer y hacer explícitos los fines y las causas por las cuales los sujetos sociales están llamados a contribuir ordenadamente a la suma de esfuerzos que toda eficiencia requiere si ha de fructificar en resultados prácticos" (Orduna, 2008, p.47). En nuestra opinión, la eficiencia económica, como criterio de decisión, tiene que hacer referencia a los valores fundamentales del sistema de convivencia, por ejemplo. Es decir, se entiende que la Economía no es una ciencia que solo maneja medios o instrumentos, pues no sería científico relegar a lo político la cuestión de los fines (Ibídem, pp.48 y ss.).

\subsubsection{Preferencias subjetivas y bienestar}

Entrando ya en el plano histórico, se había mencionado cómo el utilitarismo situó el bienestar social en la suma del bienestar de cada uno de los individuos y cómo dicho bienestar se identificó con la preferencia subjetiva e individual por bienes de índole material. Pues bien, la eficiencia económica, vinculada entonces con la mayor utilidad posible (individual y social), adopta ahora las herramientas que le proporcionará el marginalismo para definir la preferencia de unas situaciones-elecciones frente a otras. Si la idea de eficiencia como maximización de la producción se encontraba ya presente en las aportaciones económicas desde la tradición escolástica, la de eficiencia como maximización de la utilidad personal e individual (y por adición la social) era un concepto cuya gestación y desarrollo se debió especialmente a este periodo.

Así lo refleja la generalizada concepción de que eficiencia implica que más es mejor (Okum, 1975, p. 2), entendiendo por más la mayor capacidad de la gente de comprar más bienes y asumiendo que las elecciones individuales son expresión de lo que realmente mejora la situación de cada uno. No obstante, hay incluso entre los economistas quien se pregunta si, bajo un criterio diferente, podría ponerse en duda si a la gente le beneficia una mayor producción de determinados bienes como el alcohol, los cigarros, o los coches caros. Lo cual conduce a una pregunta más interesante aun, “¿Existen criterios conforme a los que pueda valorarse el bienestar que sean superiores a la mera observación de las elecciones de la gente?". Lástima que Okum renuncie a explorar una respuesta (Ibídem, p. 3$)^{18}$.

\footnotetext{
${ }^{18}$ Traducción propia.
} 


\section{Zulema Calderón Corredor}

\subsubsection{La ley de la utilidad marginal decreciente}

Aunque la eficiencia económica se identifica en general con la ausencia de derroche en los recursos, su significado más completo lo alcanza cuando esta eficiencia productiva va acompañada de eficiencia en su asignación a quien más lo necesita o lo valora. Aquí es donde entra en juego la idea del valor subjetivo de los bienes y de la utilidad marginal del agente e implica que la eficiencia será mayor cuanto mayor sea la utilidad marginal o beneficio psicológico de quien recibe o adquiere el bien. Esta conclusión está basada en la ley del decrecimiento de la utilidad marginal (H. Gossen, 1810-1858) e implica básicamente que tanto adicionales cantidades de renta como de consumo producen una utilidad menor en el agente económico pues la intensidad de la utilidad disminuye con su satisfacción. Esto significa que la utilidad derivada del consumo de un bien será mayor en las primeras unidades consumidas del mismo. Las premisas anteriores se fundamentan en la apreciación subjetiva de las necesidades del sujeto, la libertad en la fijación de los fines y en la naturaleza material o sensible de las necesidades, pues solo a estas les es de aplicación el fenómeno de la saturación implícito en le Ley de la utilidad marginal decreciente. El conjunto de medios-fines respecto de los que puede hacerse una apreciación de eficiencia asignativa de este tipo no incluye aquellos bienes a los que no les resulta de aplicación la Ley de la progresiva saturación (la amistad, la fidelidad, la honradez, el bien común, etc.). Se trata de bienes cuya naturaleza les hace deseables en la mayor medida posible porque no satisfacen necesidades materiales o sensibles, bienes que, como muchos de los materiales, responden a necesidades que derivan de cómo está hecho el hombre y del fin al que por naturaleza tiende. Quedando estos bienes fuera de su consideración, los procesos asignativos serán eficientes solo para determinados conjuntos de bienes no suficientes para atender a otras necesidades humanas que también pueden entrar dentro del objeto de la Economía. El abanico de necesidades humanas desde el que se mide la utilidad marginal y con ello la eficiencia en la asignación, responde a una visión incompleta del hombre, pues ignora otras necesidades (morales, religiosas y relacionales, fundamentalmente) respecto de las que no se cumplen los presupuestos marginalistas. Desde Descartes el hombre ha ido reservando sus certezas a lo que él puede pensar, a su percepción subjetiva, perdiendo así de vista toda certeza objetiva sobre su naturaleza, fines y deberes morales. Este vacío lo viene a llenar la propia experiencia psicológica del sujeto, su sentimiento, ahora de placer o de utilidad, ahora de dolor (Gómez Fernández, 1992, pp.30 y ss.) ${ }^{19}$.

\footnotetext{
${ }^{19}$ Este planteamiento, consecuencia lógica de la evolución epistemológica y antropológica ya comentada, coincide con la denuncia que realiza el profesor Gómez Fernández acerca de la pretendida neutralidad metafísica de la Teoría Económica. En su razonamiento incluye además algún detalle acerca de cómo tanto los economistas clásicos como los neoclásicos (F. Edgeworth, W.S. Jevons, L. Walras) reducen las necesidades morales al plano del sentimiento.
} 


\subsubsection{El individualismo metodológico ${ }^{20}$}

La cuestión acerca de si las ciencias sociales y por ello la Economía deben proceder en una línea individualista u holística, es un punto de tensión tradicional. Se ha afirmado (Calle, 2001, pp. 35-36) que "el individualismo metodológico excluye todas las proposiciones macroeconómicas que no pueden ser reducidas a proposiciones microeconómicas", debiendo de haber algo de erróneo en un principio metodológico que tiene consecuencias tan devastadoras.

Esta metodología, al rechazar implícitamente la idea aceptada por los clásicos de que puede tener sentido vincular los fenómenos económicos con el estudio de los grupos, está rechazando la pretensión de que una colectividad pueda funcionar como un organismo autónomo o que éste pueda influir en cómo actúan sus miembros. Conforme a este planteamiento, el concepto de eficiencia neoclásico resulta difícilmente compatible con la idea de un bien común compartido en el que tienen efecto las elecciones individuales y cuya existencia no solo puede a su vez conformar dichas decisiones sino que genera bienes adicionales tanto para individuos como para los grupos en los que éste participa.

\subsubsection{La hipótesis maximizadora}

La premisa maximizadora o de comportamiento racional que se presume en la acción económica deja fuera procesos de asignación en los que la motivación del agente es diversa. Quedaría fuera del comportamiento racional y eficiente la identificación y búsqueda de satisfacción respecto de las necesidades ajenas al sujeto, teniendo éstas la relevancia que tienen en un ser relacional y social como es el hombre. Es decir, quedarían fuera de su consideración todos los procesos asignativos que no responden al esquema del intercambio de equivalentes, sino a un acto de benevolencia o de gratuidad.

Esta intuición se hace explícita en algunos economista como A. Marshall (1920, p. 11) 21, quien después de haber observado que "sin duda los hombres, incluso ahora, son capaces de servir una causa no egoísta mucho más de lo que se pueda creer", afirma que "el máximo objetivo del economista es descubrir como ese activo social latente puede desarrollarse más rápidamente y ponerse a producir de la manera más inteligente posible”. Estas reflexiones son coherentes con la naturaleza social del hombre y por ello con la forma en la que las relaciones interpersonales configuran la identidad de la persona. En estas relaciones el valor se

${ }^{20}$ La idea fundamental que subyace tras la perspectiva del individualismo metodológico es que todo lo que ocurre en una sociedad tiene que ser explicado a partir de las decisiones individuales de las personas que componen esa sociedad.

${ }^{21}$ Traducción propia. 
encuentra en la relación en sí misma, por lo que les son aplicables unos principios distintos a los que pueden encontrarse en el intercambio de equivalentes. Así por ejemplo, aunque las relaciones de reciprocidad exigen cierto equilibrio entre lo que uno da y lo que espera obtener, esto puede variar según estén presentes disposiciones morales como la simpatía, la solidaridad o la benevolencia. Por otro lado "hay mucha más libertad en la reciprocidad que en el intercambio de equivalentes" pues en el primer caso la transferencia que hace el sujeto es absolutamente voluntaria e independiente de la del otro sujeto (Zamagni, 2006, pp. 36-46).

Musgrave, por su parte, cuando afirma que "los humanos..., son seres sociales, y sus satisfacciones no se obtienen de modo aislado" (1981, pp. 144-145), reconoce el aspecto relacional del ser humano y el hecho de que las utilidades individuales pueden ser interdependientes. No obstante, somete el estudio de situaciones representativas de su carácter relacional, como las donaciones, a las limitaciones antropológicas del agente neoclásico ${ }^{22}$. En nuestra opinión, las limitaciones que apunta Musgrave acerca de las redistribuciones voluntarias, derivan en parte de la propia caracterización del agente económico utilizado por la economía ortodoxa y de su insistencia en el uso del presupuesto optimizador. Experiencias humanas como la benevolencia o la filantropía, resultan difícilmente "encajables" en categorías conceptuales tan limitadas como la utilidad individual.

Esta hipótesis responde a la concepción individualista y atomizada de la sociedad que la Modernidad ha dejado como herencia en la cultura. De hecho, la existencia de comportamientos sociales que se alejan de la racionalidad instrumental presente en el intercambio de equivalentes, como la reciprocidad o incluso el altruismo en sentido puro, han permitido afirmar la compatibilidad de los sistemas de mercado con diversas matrices culturales (Zamagni, 2006, p. 50). Además, este "grado de compatibilidad no carece de efectos sobre la eficiencia misma del sistema; lo que quiere decir que una cultura marcadamente individualista tenderá a producir, caeteris paribus, resultados diferentes, en términos de bienestar y productividad, con respectos a los asociados a una cultura de la reciprocidad" (Ibídemp, p.50). En opinión de S. Zamagni, el aumento de personas relacionalmente orientadas en la sociedad genera resultados superiores también en sentido económico a los asociados a comportamientos individualistas. En estos casos, a diferencia de la mano invisible de A. Smith por la que sujetos auto-interesados promueven sin quererlo "el bien común", los sujetos que practican la reciprocidad consiguen, más allá de su propia intención, también el interés personal.

\footnotetext{
${ }^{22}$ Trata de demostrar cómo la redistribución voluntaria de rentas puede tratarse en términos de "óptimo de Pareto" pues con una donación voluntaria "alguien gana y nadie pierde". A la luz de ese análisis, concluye afirmando el papel del Estado en materia de redistribución y como consecuencia de las limitaciones de dichas redistribuciones voluntarias.
} 


\subsubsection{La eficiencia paretiana}

La eficiencia económica "en el sentido de Pareto" ${ }^{23}$ es la forma de entender la eficiencia que predomina en la teoría neoclásica y que se desarrolló para superar las dificultades de medición derivadas de la teoría marginalista de la utilidad cardinal. Este concepto es el que tienen en la cabeza los economistas cuando se refieren a la eficiencia económica y es el que se enseña en las disciplinas económicas que se imparten en las Universidades ${ }^{24}$. El criterio paretiano como criterio de valoración social, permite diseñar procedimientos de decisión por unanimidad, es individualista, no precisa de mediciones absolutas ni de comparaciones interpersonales en materia de felicidad, y es condición necesaria pero no suficiente de la justicia (Calsamiglia, 1988, pp. 305-335). Se trata de un concepto de carácter estricto (Musgrave, 1981, p. 88), pues está formulado de tal forma que permite separar dos de los problemas básicos a los que trata de dar respuesta la Economía: el de la asignación de factores y bienes y el de la distribución de renta y riqueza. Es decir, la eficiencia entendida en el sentido de Pareto tiene en cuenta únicamente la cuestión de la asignación y deja al margen el de la distribución de renta y riqueza. De aquí se deduce que la eficiencia económica paretiana, deseable para las decisiones individuales y para el mercado, no está vinculada a consideraciones de equidad, lo cual le otorga al Estado una buena dosis de legitimidad en la realización de la justicia (Stiglitz, 2000, pp. 111 y ss).

El grueso de las críticas al criterio de eficiencia paretiano señala que se trata de un criterio valorativo que no tiene en cuenta la cuestión de la distribución de la renta. Esta denuncia, aun pudiendo estar justificada, participa de la cortedad de visión de la cultura moderna en cuanto al diagnóstico de los males sociales. Contribuye, además, a convertir a la desigualdad en materia de renta en la gran legitimadora de la intervención pública, distrayendo con ello la atención de la responsabilidad social de los grupos e instituciones

\footnotetext{
${ }^{23}$ Su definición de eficiencia se encuentra referida a situaciones de distribución (asignaciones de bienes) o a situaciones de producción (asignaciones de factores productivos). En relación a las primeras, las asignaciones de recursos que tienen la propiedad de que no es posible mejorar el bienestar de ninguna persona sin empeorar el de alguna otra se dice que son eficientes u óptimas en el sentido de Pareto. Respecto a las segundas se afirma que una situación de producción en la que no es posible aumentar la cantidad de ningún bien sin reducir la cantidad producida de otros es eficiente u óptima en el sentido de Pareto. En ambos casos se encuentra implícita la idea de ausencia de despilfarro de bienes o de recursos, lo cual, desde la hipótesis que manejan muchos economistas respecto de la escasez de estos recursos, otorga al criterio de eficiencia paretiano un significativo valor normativo que transcenderá incluso la disciplina puramente económica.

${ }^{24}$ Referencias a la eficiencia "en sentido de Pareto" que se enseña en las aulas de nuestras universidades pueden citarse entre otros, los siguientes manuales: SLOGAN, JOHN, Introducción a la microeconomía. $3^{\circ}$ edición. Edit. Prentice Hall. Madrid. 1997. cap. 11; ROSEN, HARVEY S., Manual de Hacienda pública. op. cit., cap. 3; STIGLITZ, JOSEPH E., La economía del sector público. op. cit., cap.3; ALBI, EMILIO, GONZÁLEZ PÁRAMO, JOSÉ M., ZUBIRI, IGNACIO, Economía Pública II. editorial Ariel, Barcelona. 2000. cap. 1.
} 


\section{Zulema Calderón Corredor}

intermedios y de los propios individuos. Entre los parámetros del esquema anterior se mueven muchas propuestas dirigidas a encontrar una solución de compromiso entre la eficiencia económica y la intervención pública, propuestas que carecen de las herramientas conceptuales, filosóficas y antropológicas, para ahondar en las razones del problema y proponer soluciones más creativas $^{25}$.

Por el contrario, no es frecuente encontrar críticas al criterio paretiano de eficiencia que cuestionen las limitaciones antropológicas de un índice de medida como el del bienestar. Esto es, críticas que saquen a la luz la pobreza valorativa de un modelo basado en que un colectivo humano subjetiva e individualmente decide por unanimidad que un cambio asignativo no perjudica al bienestar de nadie. En el camino vuelve a quedarse el intento de utilizar un índice más representativo de la bondad de una asignación de bienes que vaya más allá del bienestar psicológico o material subjetivo que produce en los individuos. Un índice capaz de incorporar en el papel de la economía la constante pregunta por la posible existencia de unos fines objetivos, compartidos y comunes y por los posibles contornos del bien común en cada situación espacial y temporal concreta.

\subsubsection{Bienestar social e intervención estatal}

El concepto paretiano de eficiencia vio proyectado su valor normativo particularmente con la llamada Economía del bienestar. Esta rama de la Economía aportó un marco de referencia para evaluar la intervención pública aportando criterios de deseabilidad social en términos de bienestar social. Al mismo tiempo se pusieron de manifiesto situaciones como los fallos de mercado o las externalidades (A. Pigou, 1877-195926), que afectaban negativamente a la eficiencia y sobre los que el Estado estaba llamado a intervenir. Las propiedades de coordinación económica espontánea de la "mano invisible" se revelan ahora como insuficientes y dan paso a modelos económicos dónde el Estado legitima su papel como garante de la eficiencia.

\footnotetext{
${ }^{25}$ Como muestra puede verse la propuesta de Kuttner en relación al desarrollo de una economía social de mercado. (Kuttner, 1999, pp, 119-124). Utilizando frecuentes comparaciones entre países con distinto grado de regulación en los mercados y protección social, trata de mostrar cómo la eficiencia económica no está reñida con una cierta regulación en los movimientos de capital o en el mercado laboral, un Estado de bienestar que asegure servicios sociales y prestaciones públicas, una política de ayudas a los países subdesarrollados o una mayor valoración de la economía real sobre la financiera. Concluye abogando para que los gobiernos progresistas se unan "para asumir de una vez por todas la tarea de imponer la economía social de mercado en nuestros países". En nuestra opinión, se trata de una mirada sobre el mercado dirigida a compensar sus excesos y efectos adversos desde fuera, desde la intervención regulatoria, sin ser un poco más ambicioso en dirigirse al problema antropológico y cultural subyacente.
}

${ }^{26}$ Economics of Welfare (1920) 


\section{ALGUNAS CONCLUSIONES}

Conforme al análisis realizado se puede afirmar que los elementos antropológicos que, en nuestra opinión, limitan el valor explicativo del concepto moderno de eficiencia económica, no han estado siempre presentes en el estudio económico de la acción humana y en el pensamiento económico histórico más relevante sobre la eficiencia. A continuación se incluye un cuadro resumen que recoge la evolución de los elementos antropológicos y filosóficos representativos de las etapas más relevantes de la historia del pensamiento económico.

\begin{tabular}{|c|c|c|}
\hline APORTACIONES & FILOSOFÍA & ANTROPOLOGÍA \\
\hline $\begin{array}{l}\text { OIKONOMIA- } \\
\text { Aristotelismo }\end{array}$ & $\begin{array}{l}\text { Metafísica = causas } \\
\text { Realismo clásico }\end{array}$ & $\begin{array}{l}\text { Naturaleza humana } \\
\text { Vida buena }=\mathrm{T}^{\mathrm{a}} \text { de la virtud } \\
\text { Hombre social y político } \\
\text { Teleología } \\
\text { Acción humana=acto moral }\end{array}$ \\
\hline $\begin{array}{l}\text { ESCOLÁSTICA } \\
\text { (S. IX-XVII) }\end{array}$ & $\begin{array}{l}\text { Metafísica } \\
\text { Teología moral-economía } \\
\text { Justicia y eficiencia }\end{array}$ & $\begin{array}{l}\text { Moral = orden natural } \\
\text { Hombre social } \\
\text { Contexto ético-religioso } \\
\text { Bien común }\end{array}$ \\
\hline $\begin{array}{l}\text { MERCANTILISMO } \\
\text { (S. XVI-XVIII) }\end{array}$ & $\begin{array}{l}\text { Nominalismo } \\
\text { Racionalismo } \\
\text { Empirismo } \\
\text { Utilitarismo }\end{array}$ & $\begin{array}{l}\text { Moral = razón } \\
\text { Hacia el individualismo } \\
\text { Contrato social } \\
\text { Interés político/individual/social }\end{array}$ \\
\hline $\begin{array}{l}\text { ECONOMÍA } \\
\text { CLÁSICA } \\
\text { (S. XVIII-XIX) }\end{array}$ & $\begin{array}{l}\text { Metafísica = no científico } \\
\text { Racionalismo } \\
\text { Intelectivo/ Sensitivo } \\
\text { Utilitarismo } \\
\text { Liberalismo }\end{array}$ & $\begin{array}{l}\text { Individualismo } \\
\text { Hombre egoísta } \\
\text { Mecanicismo } \\
\text { Acción humana abstracta } \\
\text { Libertad=arbitrio } \\
\text { Interés individual } \\
\end{array}$ \\
\hline $\begin{array}{l}\text { ECONOMÍA } \\
\text { NEOCLÁSICA } \\
(\text { S. XIX-XX) }\end{array}$ & \begin{tabular}{|l} 
Idealismo \\
Cientificismo \\
Utilitarismo \\
Positivismo científico \\
Individualismo metodológico \\
Fines=acientífico
\end{tabular} & $\begin{array}{l}\text { Razón = maximización bienestar } \\
\text { Felicidad = Bienestar } \\
\text { Subjetivismo } \\
\text { Homo Oeconomicus } \\
\text { Interés individual/interés general }\end{array}$ \\
\hline
\end{tabular}

Fuente: elaboración propia

Las aportaciones doctrinales embrionarias sobre la acción económica incorporaron juicios de valor basados en un ideal de "vida buena "o "naturaleza humana" que permitía definir una jerarquía en los medios y en los fines objeto de análisis. 


\section{Zulema Calderón Corredor}

Desde esa jerarquía se podía evaluar la acción humana también desde un punto de vista económico. No obstante, la consideración de la acción humana económica como un acto de libertad moral va perdiéndose desde que las aportaciones de la doctrina escolástica dejan de proyectar su influencia (siglo XVI-XVII). Con el nominalismo se comienza a dudar del poder de la razón humana para llegar a las verdades esenciales sobre el hombre. Al prescindir de la teleología, pieza clave del aristotelismo, se hace implanteable la pregunta por la vida que es buena para el ser humano o por sus fines.

Este proceso hacia la "orfandad" teleológica de la economía (algún autor ya hemos visto que lo denomina "polivalencia teleológica") se ve también afectado por el creciente individualismo que durante la Modernidad se instala en las teorías político-sociales y en los modelos antropológicos referentes de la ciencia. Del hombre social aristotélico se llega al "egoísta amable" del S. XVIII. Al mismo tiempo la utilidad se adopta como criterio de evaluación económica de la acción, ignorando la riqueza y pluralidad de aspectos que influyen sobre la motivación humana.

Por su parte, el modelo de persona y las propiedades de la acción humana sobre los que se elaboran las teorías económicas, van propiciando un modelo antropológico empobrecido y alejado de la realidad. A la ausencia de fines comunes se une desde la Ilustración la separación de lo racional y lo intelectivo en el hombre, convirtiendo a la acción humana en una operación racional y abstracta y a la libertad en puro arbitrio. Desde el siglo XIX las ciencias sociales como la Economía experimentan gran atracción por las ciencias naturales y sus metodologías. Ello permite que por influencia del positivismo científico el agente neoclásico pierda rasgos esenciales definitorios de la persona. Este modelo de agente se convierte en un mero optante, carente de narrativa y proyecto vital, incapaz de actuar por motivaciones transcendentes y cuya racionalidad se identifica con un comportamiento maximizador de medios-fines económicamente valorables.

Las consecuencias derivadas del proceso anterior son de diversa índole, limitándonos aquí a señalar solo algunas.

Los desarrollos doctrinales en torno a un criterio de bondad como la eficiencia, al no incorporar la pregunta sobre sobre los fines, limitan las posibilidades que tiene la Economía de transformar la realidad humana para mejorarla. Por su parte, las apreciaciones individuales sobre la utilidad o el bienestar, han comenzado a revelar su insuficiencia como criterios medidores de bondad en las decisiones económicas (Amartya Sen, 1933) ${ }^{27}$ o en contextos sociales en los que

${ }^{27}$ Amartya Sen, premio nobel de economía en 1998, pone en cuestión el utilitarismo y propone incorporar bienes como la libertad y la justicia en el cálculo del desarrollo económico. Sen representa una excepción entre los economistas del siglo XX por su insistencia en preguntarse cuestiones de carácter valorativo que han sido abandonadas en la discusión económica por tratarse de cuestiones "no científicas". 
está presente un interés común (Elinor Ostrom, 1933-2012)28. La búsqueda de neutralidad por parte de la Economía, al despreciar el análisis de apreciaciones de carácter valorativo que están siempre presentes en la acción humana como acto de libertad moral (Gonzalo, 2010, pp. 104 y ss), impide proponer un concepto más valioso de eficiencia como criterio humano de elección.

Las limitaciones antropológicas del agente neoclásico reducen el potencial explicativo y valorador de un criterio normativo como el de eficiencia económica, criterio parcial o completamente inaplicable a procesos asignativos relativos a bienes no valorables monetariamente (relacionales, espirituales, religiosos, etc.), o no reconducibles a la lógica de los equivalentes (contextos de reciprocidad, benevolencia, filantropía, gratuidad, etc) y que son de gran transcendencia en la vida humana individual y social.

\section{BIBLIOGRAFÍA}

ALCÓN YUSTAS, Ma F. (1994), El pensamiento político y jurídico de Adam Smith. La idea de orden en el ámbito humano, Universidad Pontificia Comillas, Madrid.

ARGANDOÑA, A. (1994), "Sobre las motivaciones humanas: un enfoque unificador", en Rubio, R. y Ureña, E., Economía y dinámica social. Reflexiones acerca de la acción humana ante un nuevo ciclo histórico (pp. 147-166), Unión Editorial y Universidad Pontificia Comillas, Madrid.

ARISTÓTELES, La política. Edición preparada por Carlos García Gual y Aurelio Pérez Jiménez (1981) 2ª ed., Editora Nacional, Madrid.

Metafísica. Edición trilingüe por Valentín García Yebra (1990), $2^{\text {a }}$ ed. [19701], Gredos, Madrid.

Ética nicomaquea. Traducción y notas de Patricio de Azcárate (2004), Losada, Buenos Aires.

CALLE SAIZ, R. (2001), "La relevancia de la metodología para la Ciencia de la Economía: unas reflexiones orientativas", Revista de Economía Aplicada e historia económica, núm. 8. pp. 35-36.

CALSAMIGLIA, A. (1988), "Justicia, eficiencia y Derecho”, Revista del Centro de Estudios Constitucionales, núm. 1, pp. 305-335.

CONILL SANCHO, J. (2004), Horizontes de economía ética, Tecnos, Madrid. CRESPO, RICARDO F. (2005), “Antropología, escuela austriaca y resultados comparados desde el punto de vista de la libertad”, en Rubio de Urquía,

\footnotetext{
${ }^{28}$ Elinor Ostrom fue la primera mujer en recibir un premio nobel en Economía, en el año 2009. El Premio fue compartido con Oliver E. Williamson por su análisis de la "gobernanza económica”, especialmente de los recursos compartidos. Ostrom analiza también elementos antropológicos alternativos como la confianza, la reciprocidad y la cooperación en las relaciones económicas.
} 
R. et alt. (edit), Estudios de teoría económica y antropología (pp. 271-302). Madrid: Unión Editorial.

FERNÁNDEZ BLANCO, V. y PRIETO RODRÍGUEZ, J. (2004), "Ética y mercado en Adam Smith.”, en Álvarez García, S. y Herrera Molina, P. (coords), La ética en el diseño y aplicación de los sistemas tributarios. Documentos 16/04 (pp.49-57), IEF, Madrid.

GARCÍA DE MADARIAGA, C. (2004), La crítica al concepto liberal de justicia en AlasdairMacIntyre. Tesis doctoral. Universidad Complutense de Madrid. Disponible en: http://eprints.ucm.es/4610/1/ucm-t26075.pdf

GÓMEZ DE PEDRO, M. E. (2000), El Estado del bienestar. Presupuestos éticos y políticos. Tesis doctoral. Barcelona. Universidad de Barcelona. Disponible en: http://diposit.ub.edu/dspace/bitstream/2445/41693/1/TESISGPEDRO.pdf

GÓMEZ FERNÁNDEZ, J. M. (1992), Economía y valores humanos. Madrid: Ediciones Encuentro (primera reimpresión de 1997).

GONZALO GONZÁLEZ, L. (2010), "Recesión económica, depresión moral y recuperación socioeconómica a la luz de la encíclica Cáritas en veritate. Un apunte", Revista del Instituto de Estudios Económicos, núm. 1, pp. 103-116.

KOSLOWSKI, P. (1989), "Moralidad y eficiencia. Líneas fundamentales de la ética económica”, Cuadernos de Empresa y Humanismo, núm. 7, pp. 1-89.

KUTTNER, R. (1999), "Economía social de mercado y eficiencia económica", Leviatán. Revista de hechos e ideas, núm. 77-78, pp. 119-124.

MACINTYRE, A. (1994), Justicia y Racionalidad. Pamplona: Eunsa. (2009), Tras la Virtud, Crítica, Barcelona.

MARÍAS, J. (1981), Historia de la Filosofía 33 ${ }^{a}$ Ed. [1941ㄹ], Revista de Occidente, Madrid.

MARSHALL, A. (1920), Principles of Economics, $8^{a}$ ed. [18901]. London: Macmillan and Co. Versión on-line: http://files.libertyfund.org/files/1676/ Marshall_0197_EBk_v6.0.pdf (2-04-2015).

MARTÍNEZ-ECHEVARRÍA Y ORTEGA, M. A. (2005), "Una antropología para el agente económico”, en Rubio de Urquía, R. et alt. (edit), Estudios de teoría económica y antropología (pp. 513-533), Unión Editorial, Madrid. MILLÁN PUELLES, A. (1976), Sobre el hombre y la sociedad, Rialp, Madrid.

MUSGRAVE, R. A Y MUSGRAVE, P. B. (1981), Hacienda pública teórica y aplicada, Instituto de Estudios Fiscales, Madrid.

NEGRO PAVÓN, D. (2008), La situación de las sociedades europeas. La desintegración del êthos y el Estado, IIES, Francisco de Vitoria y Unión Editorial, Madrid.

OKUM, A. M. (1975): Equality and efficiency. The big trade-off, The Bookings Institution, Washinton, D. C. 
ORDUNA DÍEZ, L. (2008), Economía y antropología ética: el problema interdisciplinario de las Ciencias Sociales ( $2^{a}$ edición), Compañía española de reprografía y servicios, Madrid.

PÉREZ DE AYALA, J. L. (1976), Introducción a una teoría pura de la economía política, Edersa, Madrid.

RATZINGUER, J. (1985), "Economía y responsabilidad moral”, traducción de Fernando Monge, Introducción al simposio sobre "Iglesia y economía, y su responsabilidad para el futuro de la economía mundial, Instituto alemán de Economía y la Fundación Konrad Adenauer, Roma.

ROMERO JORDÁN, D. (2003), “Aspectos metodológicos de la economía y de la hacienda pública”, Documentos 3/03 (pp. 1-54), Instituto de Estudios Fiscales, Madrid.

ROTHBARD, M. N. (1999), Historia del pensamiento Económico. El pensamiento económico hasta Adam Smith. Vol. I, Unión Editorial, Madrid.

RUBIO DE URQUÍA, R. (1989), "Keynes hoy”, Esic-Market, abril-mayojunio, núm. 64. pp. 45-60.

(1993), "La autonomía de lo económico", Nueva Revista, núm. 31, pp. 60-80.

(1993a), "Concepciones de la acción humana, teorías de los procesos asignativos y el momento histórico actual", Revista de trabajo y seguridad social, enero-marzo, núm. 9. pp. 301-313.

(1994), "Ética, eficiencia y mercado", en Melé, D. (Coord.), Ética, Mercado y Negocios (pp. 49-71), Eunsa, Pamplona.

(1999), "La economía como dimensión antropológica y social”, en Alvira, R. y otros (Coord.), Sociedad civil. La democracia y su destino (pp. 333347), Eunsa, Pamploma.

SCHUMPETER, J. A. (1995), Historia del análisis económico, $1^{\text {a }}$ reimpresión de la edición española de 1994 (edición original de 1954), Ariel, Madrid. SIMON, H. A. (1978), "Rational Decision Making in Business Organization”. Conferencia en el acto de recepción del Premio Nobel. Versión on-line: http:// www.nobelprize.org/nobel_prizes/economic-sciences/laureates/1978/simon-lecture.pdf. (15-04-2015)

SMITH, A. (edición 1994), La riqueza de las naciones, traducción de Carlos Rodríguez Braun, Alianza Editorial, Madrid.

SPAEMANN, R. (1991), Felicidad y benevolencia [1989], versión española de José Luis del Barco, Rialp, Madrid.

SPIEGEL, H. W. (2004), The growth of economic thought. [1911] ${ }^{1} 6^{\mathrm{a}}$ reimpresión de la $3^{\circ}$ edición de 1991, Durham\&London: Duke University Press.

STIGLITZ, J. E. (2000), La economía del sector público $3^{a}$ edición, Antoni Bosh, editor, Barcelona.

STRAYER, J. (1970), On the Medieval Origins of the Modern State. Princeton, Princeton University Press, New Jersey. 


\section{Zulema Calderón Corredor}

TILLY, C. (1975), "Reflections on the history of the European state-making" en Tilly, Charles (Ed), The Formation of Nation States in Western Europe (pp. 3-83), Princeton University Press, New Jersey.

TRUYOL Y SERRA, A. (2004), Historia de la Filosofía del Derecho y del Estado. 1. De los orígenes a la baja edad media. 14ª ed., (Revista de Occidente, 1954), Alianza, Madrid.

UREÑA, E. M. (1994), "La actividad económica en el conjunto de la actividad social humana" en Rubio de Urquía, R. y Ureña, E. (ed. lit.), Economía y dinámica social (pp. 167-178), Unión Editorial y Universidad Pontificia Comillas, Madrid.

ZAMAGNI, S. (2006), Heterogeneidad motivacional y comportamiento económico. La perspectiva de la economía civil, IIES, Francisco de Vitoria y Unión Editorial, Madrid. 